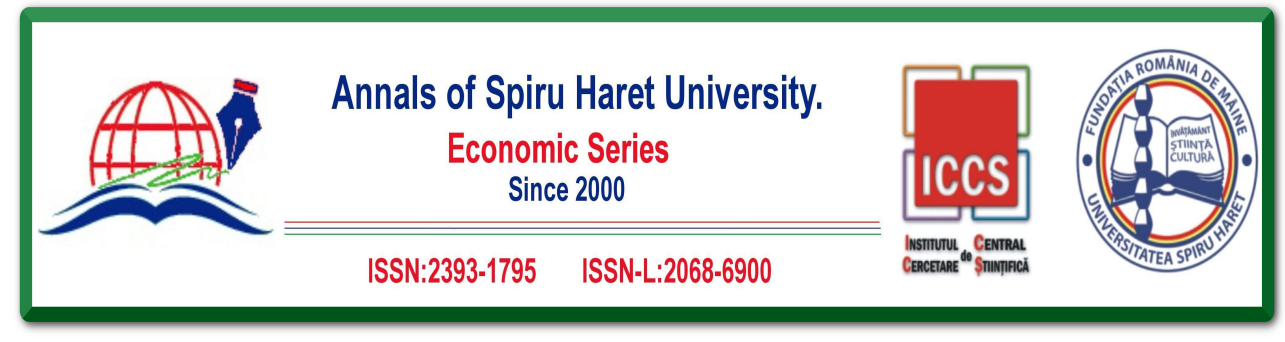

Issue 1/2019

\title{
APPROACHES TO STAFF BEHAVIOUR FROM THE PERSPECTIVE OF OPERATIONS MANAGEMENT
}

\author{
Raluca CRET OIOI ${ }^{1}$ \\ ${ }^{1}$ Spiru Haret University, Faculty of Economic Sciences, Fabricii Street, \\ no. 46G, Bucharest, 030045, Romania, Tel.: +40212.169.793, \\ Fax: +40213.169.793, Email: raluca.cretoiu@yahoo.com
}

How to cite: CREȚOIU, R. (2019). "Approches to Staff Behaviour from the Perspective of Operations Management." Annals of Spiru Haret University. Economic Series, 19(1), 83-92, doi: https://doi.org/10.26458/1915

\begin{abstract}
Operational management or operations management, as established in many speciality papers, is an area of activity that is particularly important for the successful implementation of business activities and not only. From the point of view of the connections that can be established between this concept and the one regarding the staff management, we note the direct influence that the degree of motivation in the work, the commitment and the connection to the specific values of a certain organizational culture have on the performance of the subsidiary activities of the operations management. Effective operations management implies not only the optimal use of the organization's resources, but also the engagement of staff through a behaviour whose specific features emphasize responsibility, teamwork, transparency, and commitment to assigned tasks. This article highlights the need for the staff to be connected as well as possible to the organization's values and objectives; the efficient management of operations within it is closely connected to the level of harmonization between the values and objectives, on the one hand, and the interests and motivation of the employees, on the other hand.
\end{abstract}

Keywords: operations management; behaviour; staff; organizational culture 


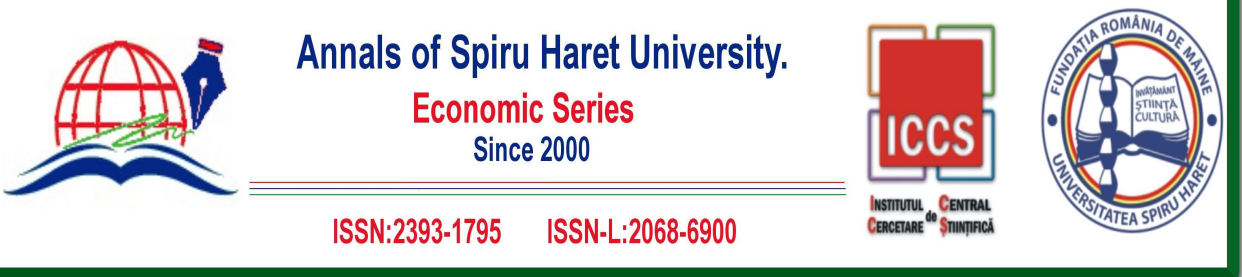

Issue 1/2019

JEL Classification: M10, M12

\section{Introduction}

Operations management interferes with most processes by which an economic agent is integratedwith its business environment. This integration effort often involves substantial changes in the way of addressing both the internal and external environment.

From the perspective of the parallels that can be made between the operational management and the processes related to the internal environment, there is a close connection between the successful management of operations and the management of human resources in its integrity.

The degree of motivation and commitment of human resources is essential to ensure the performance of a well-implemented flow of operations. Depending on the echelon they belong to and the decision-making capacity they have access to, employees exercise more or less control over the actual implementation of the operations. Therefore, their proper motivation produces immediate effects on the volume and performance of the implemented operations.

An interesting connection can be established between organizational culture, its specificity and a successful operations management. It is a well-known fact that there are firms, companies whose main characteristic of the organizational culture is represented by a true "cult" of performance, efficiency. These companies have been able to pass on their own staff a whole range of values centred on individual performances and their synergy toward an organization's performance. In these cases, organizational culture has become a base, a binder, for developing the skills required for a high performance.

Organizational culture, in terms of the possibility of optimizing the management processes, can have a major influence on the performance of the company, thus contributing to the socialization and integration of new employees, to the activity of promoting, within the organization, some values and behavioural techniques, and the birth of the idea of company affiliation.

Over the past 20 years, there has been a growing pressure on businesses to pay more attention to the environmental and resource implications of the products and services they offer and the processes they carry out [Kleindorfer et al]. 


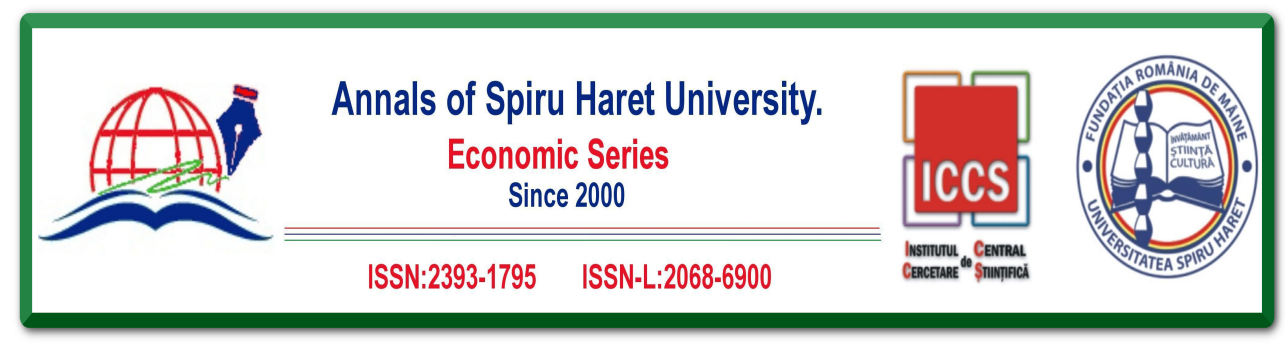

Issue 1/2019

Links between human resources management and operations management field

In order to proper emphasize our research goal regarding the influence of staff behaviour over the operations management optimization process we have conducted a systematic literature review on the topic.

Some of the cultural features seem to affect the operational management strategy (ie institutional collectivism and the avoidance of uncertainty), while the differences between the execution and the improvement of the organizational management are explained by a wider range of cultural features. On the other hand, there were found contrasting results identified, which can be explained by the limited analysis of a contextual variables that interact with the national culture [Boscari et al., 2018].

Organizational culture influences and also changes attitudes, beliefs and behaviours. If they correspond to the company's strategy, we can talk about efficiency and performance. Companies need to develop strong, strategically appropriate cultures that aim to change and adapt to the environment [Gănescu, 2008].

Operational management deepens and implements the general management knowledge in the field of processing function or other organizational functions of the industrial unit, with a view to judiciously manage the resources and adapt production to market requirements. Strategic planning will incorporate all the functions of the organization and will enable its long-term adaptation to the environment dynamic both internally and externally [Bondrea et al, 2010]. The operationalization of the management work, within the procession organization, will become essential for the adaptation to the environment, which can be achieved through its establishment at the level of all the functions and activities carried out.Thus, in any unit we can identify [Dobrin \& Moldoveanu, 2016]:

- research and development operations management;

- production operations management;

- commercial activities operations management;

- financial-accounting activities operations management;

- staffing operations management.

The strategic management of modern organizations implies promoting a development model that has evolved from the classical model based on top-down hierarchy to the model characterized by the top-down and bottom-up combined hierarchies, which implies a faster response to the challenges of the external environment.[Gherasim, 2010]

Regardless of the organizing method, the personnel activity has two categories of objectives: 


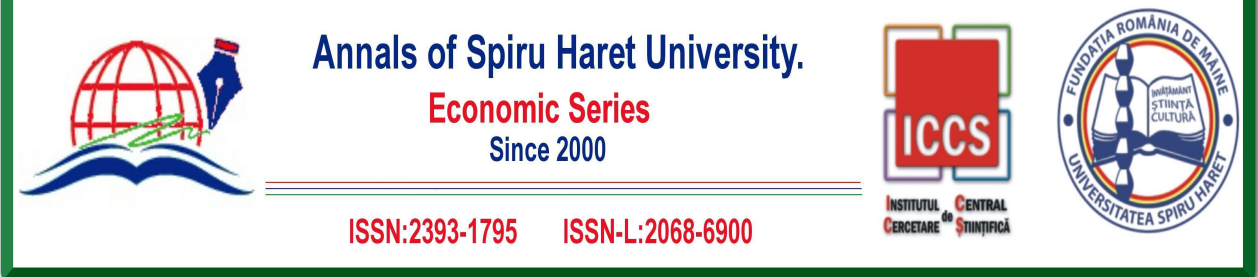

\section{Issue 1/2019}

- long-term strategic objectives, that address the organization and planning of the human resources;

- operational objectives of a technical and administrative nature, which take into account the daily management activities of the working groups.

In terms of staff behaviour, operations management investigates new developments around behavioural components - people's problems - in operations management. While these people's problems are not new, operations management has not treated them in a serious or consistent manner in the past 10 years. What is new is the emergence of a set of structured study methods and fields that allow researchers to study the issues within the operations management paradigm [Loch \& $\mathrm{Wu}, 2005$ ].

At the same time, operations management is the overall management of the business in order to achieve the highest possible level of performance within an organization. It has the role of transforming materials and workforce into goods and services in a most efficient manner, the result being maximizing the profit of an organization. To get the highest net operating profit possible, the people who form the operations management team strive to balance the costs and revenues.

Operations management represents one of the five important functions of an organization (operations - production function) and is in direct connection with the other four: R\&D, commercial, financial and accounting and staff and is based on attributes such as forecasting, organization, coordination, training and controlevaluation [Ștefănescu, 2007].

The functions of organizing, coordinating and engaging the staff are presented in the operational stage to meet the objectives included in the organization's forecasts, plans and programs. This stage corresponds to the operations management that deals with the adoption and implementation of the current decisions, most of them being applied in the production activity.

Of the three functions, the training function has the most prominent operational character and aims at involving the organization's staff in conceiving and implementing the objectives. Thus, we can conclude that staff motivation is the basis of this training function.

All the strategic and operational activities that are part of the implementation of the organization's objectives by ensuring, maintaining and systematically and efficiently utilizing the human resources at its disposal constitute the staff function within the economic organizations. In the organizational structure of the companies, the staff function is found in specialized staff departments and other compartments 86 

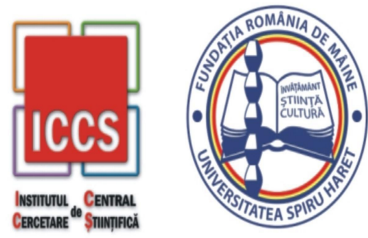

Issue 1/2019

with adequate tasks, which ensure the management of the human resources. As a result, as already mentioned, the staff of the organization represents its human resources.

The ways of influencing the group behaviour resemble those influencing the individual's behaviour, namely [Mancaş \& Jorovlea, 2013]:

-Development stage: It is characterized by dependence on other entities: group members behave formally, distantly.

- The storm stage: It takes place during adolescence and demonstrates rebellion: the members get to know each other, after which the fight for positions within the group begins.

- The rule setting stage: Coincides with that of youth and is determined by stressing self-confidence. The behaviour of group members is increasingly focused on achieving tasks, signs of cooperative behaviours and attention towards others appear, rules of social interaction behaviour are established.

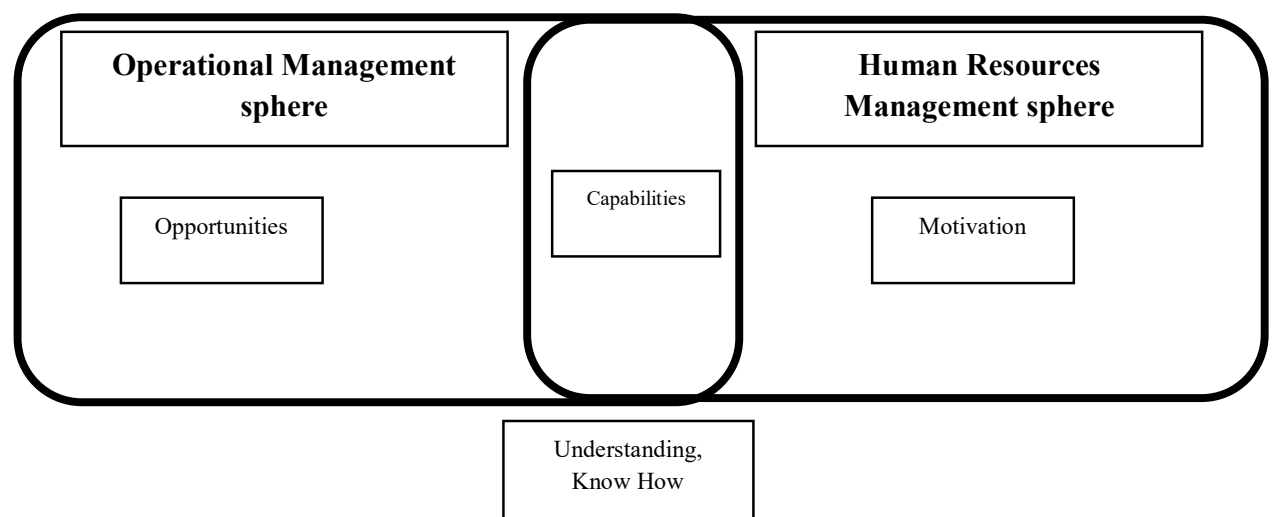

Fig. 1. The relationship between operation management sphere and human resources management sphere

Source: adaptation after Boudreau, J., Hopp, W., McClain, J.O. and Thomas, L.J., 2003. On the interface between operations and human resources management.Manufacturing \& Service Operations Management, 5(3), pp.179-202.

-Performance, maturity stage: It is dedicated to creative work and performance achievement. 


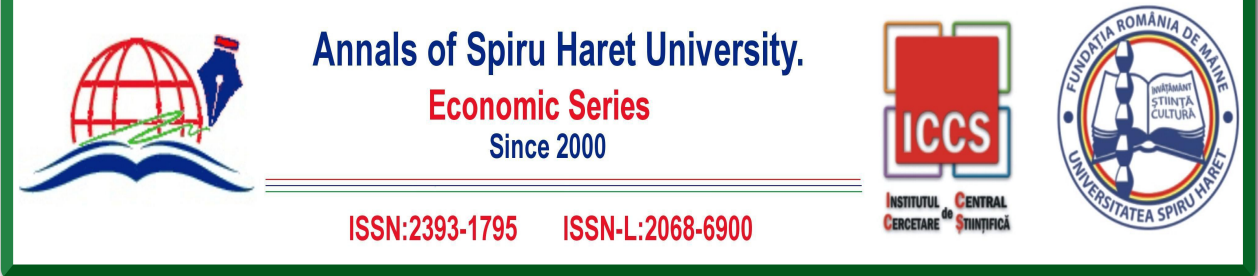

\section{Issue 1/2019}

- The decline stage is associated with pathologies related to the impossibility of growth, to the disappearance of the task or the disintegration of the formation in order to reform it in new circumstances.

From operations management perspective or in modern thinking, people are not recruited and selected to occupy certain positions, they are sought and interested in for what they can provide within the organization.

Intellectual capital is an essential resource for each organization, valuable employees being the promoters of a capital and creativity culture [Gârdan et al, 2018]. Among the current challenges faced by staff departments, we can state: support in maintaining a high standard of employee engagement, keeping employees with superior training and those with outstanding performance, developing an organizational culture that will give the company a competitive advantage, the development of leadership skills to support the company to achieve its business goals and the establishment of a learning environment that meets the employees' development needs through efficient use of technology [Badea \& Drăgan, 2018].

Stimulating young employees, involving them in working teams to help them develop new levels of responsibility is also a good way to maintain staff balance within the organization [Paşnicu \& Tudose, 2013].

A number of researchers who have studiedstaff behaviourare looking for solutions to improve results in the technological system. Due to the evolution of the stafft' behavioural characteristics, some authors have stated that operations managers will have a higher rate of success in adapting the technology to the staff rather than expecting people to adapt to its specificity.

In order to control the company's operations, managers leave their personal touch on how things are done, finding solutions to the large number of issues faced by the organization.

Therefore, each manager must have psychological knowledge, while psychological knowledge contributes to eliminating the challenges as well as answering to the questions that have arisen. Such challenges mean [Abutalibov \& Mammadov, 2010]:

- how to resolve staff conflicts in favour of the company;

- how to resist the psychological influence of partners (collaborators) or competitors;

- he way of accepting the employees and their encouragement to adopt new jobs;

- what kinds of measures can be used if the staff fails to fulfil its responsibilities or fails to fulfil its obligations;

- how to professionally eliminate stress; 


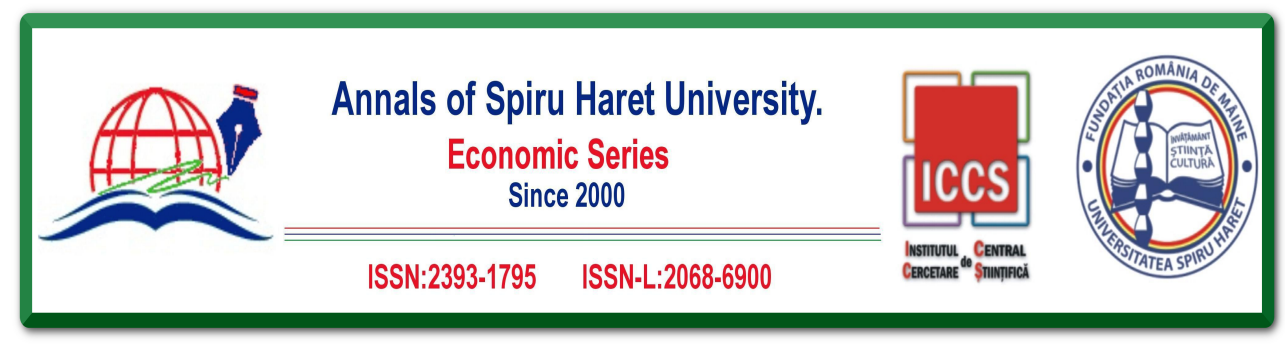

Issue 1/2019

- the best way to resolve conflicts within the company;

- how to motivate and encourage employees.

In a competitive society, the behaviour of the staff seen from the perspective of the operations management is crucial to maintaining a favourable climate in the workplace and, as mentioned above, an important requirement for business success. This is possible thanks to teamwork, through staff motivation and efficient use of communication techniques, all with the goal of constructively managing staff relationships. Moreover, a necessity for the organization is the creation of an overview, people treated equally and a suitable manager. Thus, special attention is given to fresh employees as well to those who need to integrate harmoniously into the work environment and to quickly use their own development potential [Dragomiroiu et al, 2014]. At the same time, an essential aspect is represented by the degree of incorporating a modern training and education system for employees in order to develop new useful competencies. Adult education currently has a multitude of tools that can determine the appropriate evolution of those involved in the "long life learning" [Epuran et al, 2016].The latest technologies available allow employees to be remotely trained, their easy interaction with a learning environment that simulates reality making thus possible the adaptation in a timely manner to the increased demands of jobs [Andronie, 2014].

In the success or failure of any organization, the staff's behaviour plays an essential role, and the way in which this organization's resource is managed is the problem faced by the human resources department that seeks to find the best solution in this respect. Staff's behaviour at work differs from one person to another, thus resulting a improperly behaviour of the organization's staff. Both organizational and individual factors contribute to a great extent to this type of behaviour. However, staff's inappropriate behaviour is a deliberately done action to jeopardize the good work of the organization. Such a behaviour is justified by the fact that the staff is not sufficiently motivated to be able to respond promptly to the requirements of the organization.

The more we maintain a higher level of the labour force, the more the recruitment and training costs will be minimized. Financial rewards are not always enough motivate the staff. In some situations, it may be necessary to motivate staff using other incentives, such as prizes, promotions, actions and staff reductions. It is important for the management and the staff to have effective communication 


\section{Issue 1/2019}

techniques, such as e-mail, newsletters or meetings. Communication is particularly important, especially for the purpose of providing feedback to managers, through surveys or even through discussions. It is precisely through these methods of communication that we can find in good time a solution to the difficulties that have arisen, in an alert and efficient manner. Under these circumstances, a constructive and lasting partnership can be created between the manager and the employees to contribute to the success of the organization and to the improvement of the workforce quality.

Staff evaluation is one of the most important components of the staff management system. A decisive factor in the competitiveness of any company is the relevance of studying issues related to staff performance assessment in enterprises from different industries due to the interest in solving the problem of improving staff management, which is increasingly becoming a determining factor in the competitiveness of any company. Each organization strives to keep the best possible records, create conditions for the professional qualification of growth, and at the same time get rid of the inert, low-skilled, unspoken employees. The essence of the problem and the assessment staff must be available and easy to understand for employees as part of the main production and management staff. The ultimate goal should be to use qualified recruiting staff and increase efficiency [Yanchenko \& Rosa, 2015].

Both labour outcomes and employee behaviours should be evaluated. The chosen criteria must take into account [Terracciano, 2017]:

-Organizational Objectives: Performance evaluation should be organized in accordance with the available information and its usage. Together with the real workload, this will include elements promoted by the organization in human resources policies: creativity, professional development, managerial skills, multiple qualifications, flexibility.

-Position: In choosing the tasks to be assessed - those on which the employee has control should be taken.

-Employee needs: Facilitating communication between management and employees. Employees are generally interested in promoting opportunities. They may sometimes want to talk about their position or their team, and the inability to address these problems can lead to frustration, dissatisfaction, absenteeism and even resignation.

In operations management, employee stimulation is essential as a factor to ensure the linearity and continuity of motivated productive activities. At the same 90 


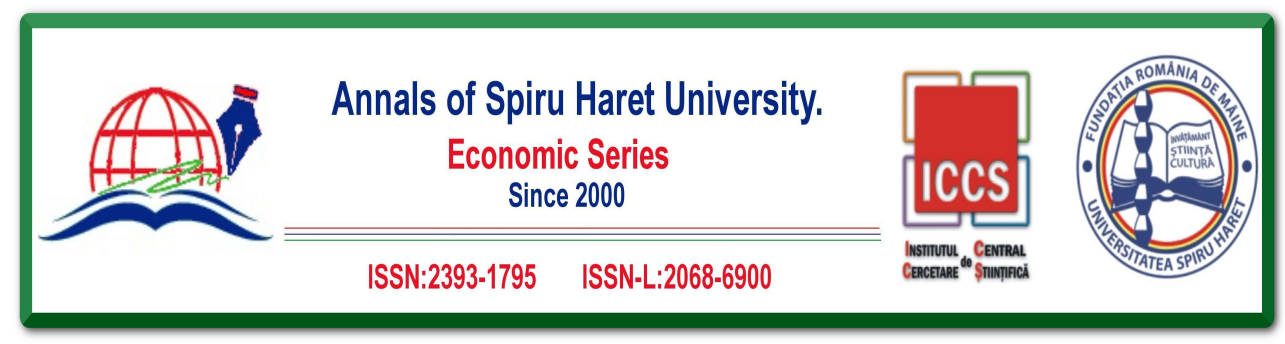

Issue 1/2019

time, stimulating human resources within the company contributes to adding efficiency to the economic and productive process of the unit [Iatagan, Meruță, 2018]. By properly motivating, the intricate value of the human capital within the organization is maintained and even elevated, a thing which can lead to increased competitiveness for the following cycles of activity [Iatagan, 2015].

\section{Conclusion and future directions of research}

Organizations have an intense concern about management's involvement in the staff behaviour at work, including about what employees are willing to offer to the organization.

Both the formulation of the staff strategy and policy and the determination of the number of persons needed are indispensable for ensuring an efficient organization of the staffing activity.

The behaviour of the operations staff is closely related to staff's motivation at work, a thing that contributes significantly both to the improvement of production processes and to maintaining a harmony between management and staff.

Nowadays, staff behaviour seen from the perspective of the operations management is responsible for the organization's evolution and, in particular, for the level it manages to reach as a business. This behaviour can be optimized and should be optimized by means of a variety of tools that have as leitmotif increase of the engagement, self-motivation and involvement of staff, especially the operational one. A healthy organization is defined by the ability to react promptly to changes in the business environment and by a perfect balance between the operationalization of efficient management principles and strategic goals and interests. Limitations of the present article are related to the fact that most of the findings and ideas exposed are based mainly on a review of the literature in the field. A quantitative type research applied within different categories of companies can test the relationship between a group of variables that are defining staff behaviour and another group of variables that are defining optimised operations management processes. Testing hypothesis regarding the statistical influence between the two groups of variables over a proper sample of companies can be very helpful in order to understand more deeply the research agenda regarding the link between the above mentioned concepts - human resources management, employee's behaviour, beliefs and commitment and optimisation of operations management within a company. 

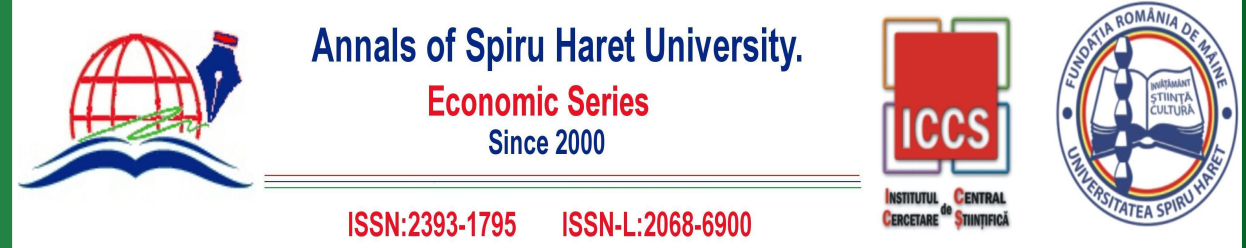

\section{Issue 1/2019}

Another future research direction can be also a qualitative type research that should be done using a sample of managers from different companies using the indepth interview technique, research that have as the main goal testing attitudes and perceptions of managers regarding the way in which operations management implementation within a company is depending on the specific employees behaviour, level of commitment and motivation. In addition to other areas of application of a company's management, operations management require specific involvement from apart the staff which technically has to do with the flow of operations itself. Testing managers opinion on this matter could bring new insights regarding the way in which modelling staff behaviour can alter positively results regarding operations management process.

We need to make sure that all progress in operations management theory leads to research that is both scientific and relevant [Walker et al, 2015].

\section{References}

[1] Abutalibov. Rasim, Rufat Mammadov. M.A. (2010). Social Responsibility, Professional Ethics, and Management. Proceedings of the 11th International Conference 2010 Ankara, Turkey, 24-27 November, p. 591,592.

[2] Andronie, M. (2014). "Distance Learning Management Based on Information Technology." Contemporary Readings in Law and Social Justice, 6(1), 350.

[3] Badea, Elena, Drăgan, Daniel (2018). Managing Partner BusinessMark., Provocarile actuale ale departamentelor de resurse umane, dezbatute la Operational HR.

[4] Bondrea, A., Gârdan, D.A., Gârdan, I. P., (2010). "The Role of Strategic Planning in Relationship Marketing.” Annals of Spiru Haret University, Economic Series, 1(4), 53-60.

[5] Boudreau, J., Hopp, W., McClain, J.O. and Thomas, L.J. (2003). On the interface between operations and human resources management. Manufacturing \& Service Operations Management, 5(3), pp.179-202.

[6] Boscari Stefania, Bortolotti Thomas, Torbjørn H. Netland \& Nick Rich (2018). National culture and operations management: a structured literature review, International Journal of Production Research, 56:18, pp. 6314-6331, DOI: 10.1080/00207543.2018.1461275.

[7] Dobrin, C., Moldoveanu, G., Management operațional. Editura ProUniversitara, București, 2016.

[8] Dragomiroiu, R., Hurloiu, I. I., \& Mihai, G. (2014). "Induction staff training." Procedia Economics and Finance, 16, 368-373. 


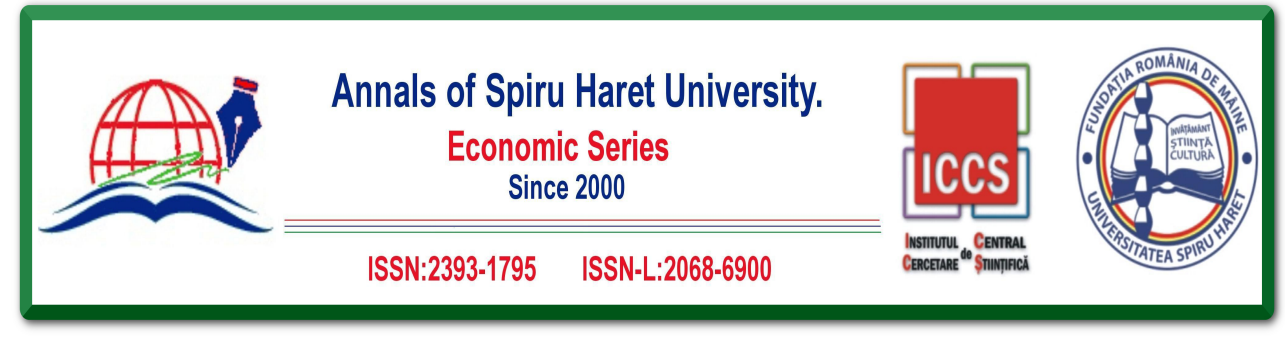

Issue 1/2019

[9] Epuran, G., Gârdan, I. P., Gârdan, D. A., \& Tescaşiu, B. (2016). "Modernisation of Higher Education in the Context of European Integration? A Comparative Analysis." Amfiteatru Economic Journal, 18(42), 351-368.

[10] Gănescu, C. (2008). "Impactul culturii organizaţionale asupra performanţelor şi competitivităţii firmelor contemporane." Strategii manageriale, Revistă editată de Universitatea Constantin Brâncoveanu Piteşti, nr. 2, pp. 41-45.

[11] Gârdan, D. A., Andronie, M., Gârdan, I. P., Andronie, I. E., Iatagan, M., \& Hurloiu, I. (2018). "Bioeconomy Development and Using of Intellectual Capital for the Creation of Competitive Advantages by SMEs in the Field of Biotechnology." Amfiteatru Economic, 20(49), 647-666.

[12] Gherasim, Z. (2010). "Competitiveness in Organizational Integrated Computer System Project Management." Annals of Spiru Haret University, Economic Series, 1(2), 215220.

[13] Iatagan, M. (2015). "Consequences of the Investment in Education as Regards Human Capital." Procedia Economics and finance, 23, pp. 362-370.

[14] Kleindorfer Paul R., Singhal Kalyan, and Van Wassenhove Luk N. (2005). Sustainable Operations Management Production and Operations Management Vol. 14, No. 4, Winter 2005, issn 1059-1478, pp. 482-492.

[15] Iatagan, M., Meruță, A. Management operațional. Editura Fundației România de Mâine, București, 2018.

[16] Loch, C. H. and Wu, Y. (2005). "Behavioral Operations Management, Foundation and Trends R in Technology," Information and Operations Management, vol. 1, no. 3, pp. $121-232$.

[17] Mancaş, Maria, Jorovlea, Elvira (2013). Revista / Journal „ECONOMICA” nr. 1 (83).

[18] Paşnicu, D., \& Tudose, G. (2013). "Youth employment and measures to increase employability during the crisis." Theoretical and Applied Economics, 20(Special II), 276-287.

[19] Ștefănescu, Roxana. Management operațional. Editura Fundației România de Mâine, București, 2007.

[20] Terracciano, N. (2017). "Performance management at the organizational level." Annals of Spiru Haret University, Economic Series,8 (2), 19-28.

[21] Walker Helen, Chicksand Daniel, Radnor Zoe, Watson Glyn (2015). "Theoretical perspectives in operations management: an analysis of the literature", International Journal of Operations \& Production Management, Vol. 35 Issue: 8, pp.11821206, https://doi.org/10.1108/IJOPM-02-2014-0089.

[22] Yanchenko, N. V. \& Rosa, A. A. (2015). Enhance the evaluation of staff performance, issue 49, pp. 169-173. 
